\title{
Hypertonicity, but Not Hypothermia, Elicits Substance P Release from Rat C-Fiber Neurons in Primary Culture
}

\author{
Allan Garland, John E. Jordan, Jonathan Necheles, Linda E. Alger, Melinda M. Scully, Richard J. Miller, Daniel W. Ray, \\ Steven R. White, and Julian Solway \\ Section of Pulmonary and Critical Care Medicine, Department of Medicine, and Department of Pharmacological and Physiological \\ Sciences, The University of Chicago, Chicago, Illinois 60637; and Department of Medicine, Evanston Hospital, Evanston, Illinois 60201
}

\begin{abstract}
Isocapnic dry gas hyperventilation provokes hyperpnea-induced bronchoconstriction in guinea pigs by releasing tachykinins from airway sensory C-fiber neurons. It is unknown whether dry gas hyperpnea directly stimulates $\mathrm{C}$ fibers to release tachykinins, or whether this physical stimulus initiates a mediator cascade that indirectly stimulates C-fiber tachykinin release. We tested the hypotheses that mucosal hypothermia and/or hyperosmolarity-physical consequences of airway heat and water loss imposed by dry gas hyperpnea-can directly stimulate $\mathbf{C}$-fiber tachykinin release. Neurons isolated from neonatal rat dorsal root ganglia were maintained in primary culture for 1 wk. Cells were then exposed for $30 \mathrm{~min}$ at $37^{\circ} \mathrm{C}$ to graded concentrations of $\mathrm{NaCl}$, mannitol, sucrose, or glycerol (0-600 mOsm) added to isotonic medium, or to isotonic medium at $25^{\circ} \mathrm{C}$ without or with $462 \mathrm{mOsm}$ mannitol added. Fractional release of substance $P$ (SP) was calculated from supernatant and intracellular SP contents following exposure. Hyperosmolar solutions containing excess $\mathrm{NaCl}$, mannitol, or sucrose all increased fractional SP release equivalently, in an osmolarity-dependent fashion. In marked contrast, hypothermia had no effect on fractional SP release under isotonic or hypertonic conditions. Thus, hyperosmolarity, but not hypothermia, can directly stimulate tachykinin release from cultured rat sensory $C$-fibers. The lack of effect of glycerol, a solute which quickly crosses cell membranes, suggests that neuronal volume change represents the physical stimulus transduced by $\mathrm{C}$-fibers during hyperosmolar exposure. ( $J$. Clin. Invest. 1995. 95:2359-2366.) Key words: hyperpneainduced bronchoconstriction • asthma • tachykinin • sensory nerves • dorsal root ganglion
\end{abstract}

\section{Introduction}

Isocapnic hyperventilation of dry gas provokes bronchoconstriction in human asthmatic subjects $(1-5)$ and in tracheostom-

Address correspondence to Julian Solway, M.D., University of Chicago, MC 6026, 5841 S. Maryland Avenue, Chicago, IL 60637. Phone: 312702-6790; FAX: 312-702-4736. Allan Garland's present address is Department of Medicine, University of Medicine and Dentistry of New Jersey, Robert Wood Johnson Medical School, New Brunswick, NJ 08903.

Received for publication 11 August 1994 and in revised form 7 December 1994.

J. Clin. Invest.

(c) The American Society for Clinical Investigation, Inc.

$0021-9738 / 95 / 05 / 2359 / 08 \quad \$ 2.00$

Volume 95, May 1995, 2359-2366 ized Hartley guinea pigs (6-9). Hyperpnea-induced bronchoconstriction (HIB $)^{1}$ is evidently stimulated by airway heat and/ or water loss in both asthmatic humans and guinea pigs, for isocapnic hyperventilation of warm, humidified inspired gas produces no change in airway caliber. Most investigators agree that the airway heat and water losses imposed by dry gas hyperpnea lead to both airway mucosal cooling and drying with consequent mucosal surface fluid hyperosmolarity. The dual physical sequelae of dry gas hyperpnea have prompted competing hypotheses that mucosal cooling or mucosal surface fluid hyperosmolarity represents the primary physical stimulus which evokes the bronchoconstrictor response to dry gas hyperpnea.

In guinea pigs, HIB is critically dependent upon tachykinin release from airway sensory nerves, for depletion of sensory neuropeptides by chronic capsaicin pretreatment ablates HIB $(9,10)$ and blockade of NK-2 receptors markedly blunts this response (11). At present, it is unknown how dry gas hyperpnea stimulates tachykinin release. It is conceivable that a physical consequence of dry gas hyperpnea directly acts on sensory Cfibers to stimulate release of their neuropeptides. Alternatively, mucosal cooling or drying may stimulate sensory neuropeptide release indirectly by first acting on another cell type to release mediators that directly or through an additional cellular/mediator cascade eventually stimulates airway C-fibers. For example, hyperosmolar mucosal surface fluid may stimulate mucosal mast cells to release mediators, an effect of osmolarity previously demonstrated in isolated mast cells outside of the airways (12).

We undertook the present study to evaluate whether either of the physical sequelae of dry gas hyperpnea-hypothermia due to heat loss, or hyperosmolarity due to water loss - can directly stimulate sensory neuropeptide release. We exposed sensory neurons isolated from the dorsal root ganglia of neonatal rats to conditions of hyperosmolarity or hypothermia, and measured fractional substance $P$ release stimulated by these exposures. We demonstrate that hyperosmolarity, but not hypothermia, can directly stimulate sensory neuropeptide release from these cells.

\section{Methods}

Primary culture of dorsal root ganglion cells. Dorsal root ganglia (DRG) were harvested from 1-5-d-old Sprague-Dawley rats after the method of Perney (13). Rats were decapitated, and the spinal columns were surgically removed and placed into ice-cold calcium and magne-

1. Abbreviations used in this paper: HIB, hyperpnea-induced bronchoconstriction; NK, neurokinin; DRG, dorsal root ganglia; CMFB, calcium and magnesium free buffer; GM, growth medium; SP, substance P; NKA, neurokinin A; AB, assay buffer; SS, supernatant sample; CS, cell sample; CGRP, calcitonin gene-related peptide. 
sium free buffer (CMFB). The columns were incised bilaterally and, under a dissecting microscope, the DRG were visualized, removed using ultrafine forceps, and placed into ice-cold CMFB. Approximately 45$50 \mathrm{DRG}$ per rat pup were obtained in this fashion in groups of 3-6 pups. After harvest, the DRG were washed twice with CMFB, transferred into $1.5 \mathrm{ml}$ of fresh CMFB, and digested by serial addition of $0.1 \%$ collagenase ( $300 \mu$ l, Sigma Chemical Co., St. Louis, MO), collagenase/Dispase (200 $\mu \mathrm{l}$, Boehringer-Mannheim, Indianapolis, IN), and 2.5\% trypsin ( $60 \mu \mathrm{l}$; GIBCO BRL, Gaithersburg, MD) for $10 \mathrm{~min}$ each. Enzymatic action was terminated by addition of $1 \mathrm{ml}$ horse serum, and the partially digested ganglia were washed and placed in isotonic growth medium (GM), consisting of Ham's F-12 (GIBCO BRL) supplemented with $1.5 \%$ fetal bovine serum, $5 \%$ heat inactivated rat serum, $100 \mu \mathrm{g} / \mathrm{liter}$ $7 \mathrm{~S}$ murine nerve growth factor (Sigma Chemical Co.), 5 grams/liter glucose, $10 \mathrm{ml} /$ liter MEM vitamin solution, $10 \mathrm{ml} / 1 \mathrm{~L}$-glutamine, $1 \mathrm{mM}$ $\mathrm{CaCl}_{2}$, and $10 \mathrm{ml} /$ liter of penicillin/streptomycin solution (GIBCO BRL). DRG cells were then mechanically dissociated by trituration through a glass pipette until the cell suspension was cloudy in appearance.

Ganglia then were plated at a density of $\sim 5$ ganglia $/ \mathrm{cm}^{2}$ into $35-$ mm Primaria plastic culture wells (Falcon Labware, Cockeysville, MD) which had previously been coated with laminin and fibronectin. Ganglion cell cultures were maintained at $37^{\circ} \mathrm{C}$ in $5 \% \mathrm{CO}_{2}$ and fed with $1.5 \mathrm{ml}$ fresh GM on the first, third, fifth, and sixth days after culturing. On the second, third, and fifth days the GM contained $10 \mu \mathrm{M}$ cytosine arabinoside (Ara-C; Sigma Chemical Co.) to suppress growth by ganglionic fibroblasts. Cultured C-fibers were studied seven days after DRG harvest, at which time over $75 \%$ of DRG cells were phenotypically Cfibers (see Results)

Demonstration of nerve cell phenotype. Dorsal root ganglion cells in primary culture were evaluated for characteristic phenotype of Cfibers as follows. Cells were grown on laminin and fibronectin-coated glass coverslips using the methods described above. Immunoreactive substance $P$ then was revealed by performing immunocytochemistry using primary anti-SP antiserum (Peninsula Laboratories, Belmont, CA) and a commercially available avidin-biotin-immunoperoxidase kit ( VectaStain). In an additional experiment, intracellular calcium concentration was measured in 15 individual dorsal root ganglion cells by digital imaging microfluorimetry according to the method of Bindokas et al. (14). Cells grown on fibronectin- and laminin-coated glass coverslips were loaded with the indicator dye fura-2 $(5 \mu \mathrm{M})$ for $15 \mathrm{~min}$ at $37^{\circ} \mathrm{C}$ followed by $30 \mathrm{~min}$ wash with saline solution (in $\mathrm{mM}: \mathrm{NaCl} 144$, Hepes $10, \mathrm{CaCl}_{2} 2, \mathrm{MgCl}_{2} 1, \mathrm{KCl} 5, \mathrm{D}$-glucose 10; $\mathrm{pH} \mathrm{7.4,} 312$ mosmol) to allow complete deesterifiction of the dye. The sample chamber then was superfused with saline solution containing $10 \mu \mathrm{M}$ capsaicin. Emitted fluorescence at $510 \mathrm{~nm}$ was recorded by digital imaging microfluorimetry using an intensified CCD camera (Hamamatsu, Hamamatsu City, Japan) coupled to a Nikon Diaphot microscope (40× Fluor objective) and software (Universal Imaging Corp., West Chester, PA) on an 80486 computer (Gateway, Inc., North Sioux City, SD). Sample illumination was supplied by a $150 \mathrm{~W} \mathrm{Xe}$ arc, and excitation wavelengths ( 340 and $380 \mathrm{~nm}$ ) were selected by computer control of a filter wheel. Typically 12 to 16 frames at each wavelength were averaged to produce ratio images at $\sim 1.0 \mathrm{~Hz}$. Intracellular calcium concentration then was calculated from the ratio of $340: 380 \mathrm{~nm}$-stimulated fluorescences as previously described (14). Data from one neuron were excluded because its resting intracellular free calcium concentration was $550 \mathrm{nM}$, greater than three times that of the other 14 neurons studied.

Exposures of cultured $C$-fiber neurons. Neurons were washed twice in an assay buffer $(\mathrm{AB})$ comprised of GM excluding sera, nerve growth factor, or penicillin/streptomycin, and including additional $0.2 \%$ fatty acid-free bovine serum albumin. To inhibit enzymatic degradation of substance $\mathrm{P}, 10 \mu \mathrm{M}$ enalaprilat (Merck, Sharp and Dohme) and $3 \mu \mathrm{M}$ phosphoramidon (Sigma Chemical Co.) also were added. Cells were exposed to individual experimental conditions by incubation for $30 \mathrm{~min}$ in $1.5 \mathrm{ml} \mathrm{AB}$ containing the experimental additives (see below) at either 37 or $25^{\circ} \mathrm{C}$ under $5 \% \mathrm{CO}_{2}$. The supernatant sample (SS) was aspirated from the culture plate and glacial acetic acid was added to 5\% final concentration; the SS then was boiled for $10 \mathrm{~min}$ and kept on ice for further processing. Cultured neurons were removed from the plastic with a cell scraper after addition of $1.5 \mathrm{ml}$ of boiling $5 \%$ acetic acid to the culture well. To liberate the remaining neuropeptides from the cell sample (CS), the solution was boiled for $10 \mathrm{~min}$ and sonicated for $\mathbf{3 0}$ s. To remove cell debris and larger proteins from both SS and CS samples, an equal volume of $0.1 \%$ trifluoroacetic acid was added and the mixture centrifuged at $10,000 \mathrm{~g}$ for $20 \mathrm{~min}$ at $4^{\circ} \mathrm{C}$. Supernatants without debris were saved for further processing.

Determination of fractional substance $P$ release. The substance $P$ content of each SS or CS was measured by ELISA, after partial purification with a C-18 Sep-Pak column (Waters, Division of Millipore, Inc., Milford, MA). The Sep-Pak purification was effected by serial passage (via gravity only) through the column of: $(a) 1 \mathrm{ml} 0.1 \%$ trifluoroacetic acid $/ 60 \%$ acetonitrile (Buffer B); (b) $15 \mathrm{ml} 0.1 \%$ trifluoroacetic acid (Buffer A); $(c)$ the sample; $(d) 15 \mathrm{ml}$ Buffer A; and $(e)$ final elution with $3 \mathrm{ml}$ Buffer B. Purified samples were dried in a Speed-Vac (Savant Instruments, Inc., Farmingdale, NY) overnight and stored at $-70^{\circ} \mathrm{C}$ until assayed.

Substance $\mathrm{P}$ assays were performed in 96 well plates (Costar Corp., Cambridge, MA) coated with $2.5 \mathrm{ng} /$ well of substance P-bovine serum albumin conjugate made by the method of Folkesson (15). Samples were assayed in duplicate. The primary antibody solution consisted of (final concentrations) 3\% goat serum, $0.1 \mathrm{M}$ phosphate buffer, $0.05 \%$ Tween-20 and $0.005 \%$ rabbit anti-SP serum (Peninsula Laboratories). The secondary antibody solution was $3 \%$ goat serum, $0.05 \%$ Tween$20,0.15 \mathrm{M} \mathrm{NaCl}$ and $0.05 \%$ peroxidase linked donkey anti-rabbit IgG solution (Amersham Corp., Arlington Heights, IL). Dried samples were dissolved in $100 \mu \mathrm{l}$ of a 1:1 mixture of absolute methanol and $0.1 \mathrm{~N}$ $\mathrm{HCl}$. A portion of each sample, as well as a series of freshly made standard solutions of SP (Peninsula Laboratories), was incubated with primary antibody solution in a 1:8 ratio for $2 \mathrm{~h}$ at $37^{\circ} \mathrm{C}$ with agitation. Then $100 \mu$ l of the combination was placed into conjugate-coated microtiter wells, and the plate was incubated with agitation overnight at $4^{\circ} \mathrm{C}$. The next day, the plate was washed three times and $100 \mu \mathrm{l}$ of secondary antibody solution was added to each well. The plate was incubated for $2 \mathrm{~h}$ at $37^{\circ} \mathrm{C}$, after which it was again washed three times. Then $100 \mu \mathrm{l}$ $o$-phenyldiamine-containing substrate solution was added to each well and the plate was incubated at room temperature, in darkness, until a gradient of color was visible across the rows of standards. The colorimetric reaction then was stopped by adding $100 \mu \mathrm{l} 2.5 \mathrm{M} \mathrm{H}_{2} \mathrm{SO}_{4}$ to each well. Optical density at $492 \mathrm{~nm}$ of each well was recorded (ThermoMax Plate Reader; Molecular Device, Menlo Park, CA), and the SP content of each sample was interpolated along the standard curve. This technique had a reproducible measurable range of $10-10,000 \mathrm{fmol}$ SP per neuron culture well, and cross-reactivity for neurokinin A was $0.1 \%$. Fractional release of substance $P$ in an experiment then was expressed as the percent of total substance $P$ released during the $30 \mathrm{~min}$ trial, calculated as $100 \times \mathrm{SS}_{\mathrm{SP}} /\left(\mathrm{SS}_{\mathrm{SP}}+\mathrm{CS}_{\mathrm{SP}}\right)$, where $\mathrm{SS}_{\mathrm{SP}}$ and $\mathrm{CS}_{\mathrm{SP}}$ are the SP contents of corresponding SS and CS samples, respectively.

Effects of specific interventions upon neuron cultures. To determine whether either hyperosmolarity or hypothermia can directly elicit tachykinin release from C-fiber neurons in primary cell culture, individual neuron culture wells were exposed for $\mathbf{3 0} \mathrm{min}$ to one of the following experimental conditions. (a) Assay buffer (AB) at $37^{\circ} \mathrm{C}$ without additives, as the unstimulated, isotonic, normothermic control; $(b)$ isotonic $\mathrm{AB}$ at $37^{\circ} \mathrm{C}$ containing $10 \mu \mathrm{M}$ capsaicin or $50 \mathrm{mM} \mathrm{KCl}$, as a positive control; (c) $\mathrm{AB}$ at $37^{\circ} \mathrm{C}$ made hypertonic by addition of increasing concentrations of mannitol (0-616 mOsm/liter added); or $(d)$ isotonic $\mathrm{AB}$ at $25^{\circ} \mathrm{C}$. To study further the relationship between hypertonicity and SP release from cultured $\mathrm{C}$-fibers, additional culture wells were exposed for $30 \mathrm{~min}$ at $37^{\circ} \mathrm{C}$ to $\mathrm{AB}$ made hypertonic by addition of graded concentrations of either $\mathrm{NaCl}$, sucrose, or glycerol (0-616 mOsm/liter). To evaluate whether hypothermia had any influence upon hyperosmolarity-stimulated release of neuropeptides, additional culture wells were exposed for $30 \mathrm{~min}$ at $25^{\circ} \mathrm{C}$ to $\mathrm{AB}$ made hypertonic by addition of 462 mOsm/liter mannitol.

To verify that SP release elicited by hyperosmolarity was not due 


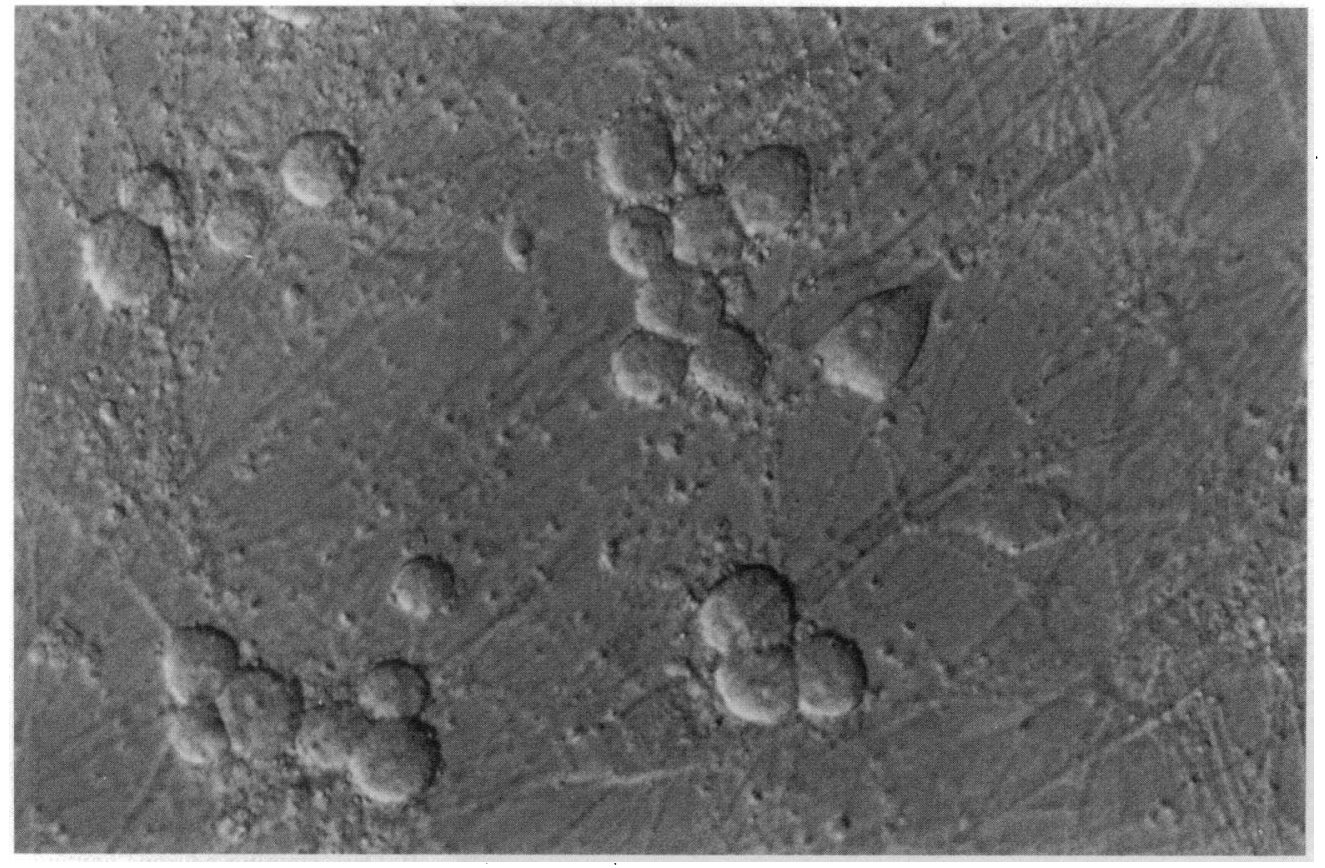

Figure 1. Phase-contrast photomicrograph of neonatal rat dorsal root ganglion cells after primary culture for $7 \mathrm{~d}$. Neurons exhibit globular cell bodies and slender axonal processes; a few fibroblasts are present in the background. to loss of C-fiber membrane integrity, separate wells of cultured neurons were exposed for $30 \mathrm{~min}$ at $37^{\circ} \mathrm{C}$, as above, to: $(a)$ isotonic $\mathrm{AB}$ as a negative control; (b) $\mathrm{AB}$ made hypertonic by addition of $462 \mathrm{mOsm} /$ $\mathrm{L} \mathrm{NaCl}$; or (c) $25 \%$ ethanol in $\mathrm{AB}$ as a positive control. After exposure, the wells were washed once with fresh isotonic assay buffer and exposed for $2 \mathrm{~min}$ to $0.004 \%$ trypan blue in isotonic $\mathrm{AB}$. Cells were washed again and examined for uptake of dye.

Data analysis. Unless otherwise indicated, all data are expressed as mean \pm SEM, and $P$ values of $<0.05$ were considered statistically significant. Comparisons among SP release in wells exposed to mannitol, hypothermia, and positive and negative controls were made using oneway analysis of variance (ANOVA). When overall significance was found, additional comparisons between each intervention to the negative control were made by Dunnett's multiple range test. Differences among dose-response relationships for different solutes were tested using ANOVA for each concentration studied, with subsequent Bonferroni correction for the four comparisons made. This correction introduces an additional measure of stringency in the analysis. For any concentration at which a significant effect was discovered by such an ANOVA, Scheffé multiple range analysis was performed to determine which solute(s) differed from the others. Comparisons between hypothermia and normothermia in either isotonic or hypertonic conditions were made by unpaired $t$ test.

\section{Results}

Demonstration of $C$-fiber phenotype. Studies reported here were performed using 157 culture wells of neonatal rat DRG neurons. The typical appearance of these cells in culture is shown in Fig. 1. Over $75 \%$ of DRG neurons characterized were phenotypically C-fibers, as evidenced by: (a) strong immunoreactive staining for substance $P$ (Fig. 2), and (b) increased intracellular calcium ion concentration after treatment with $10 \mu \mathrm{M}$ capsaicin (Fig. 3 ). In addition, the mean total SP content of DRG neuron culture wells was $1630 \pm 1144 \mathrm{fmol}$ per well (mean \pm SD). The precise identity of the remaining, non-C-fiber neurons was not established, though presumably they belong to another of the six classes of neurons identified within DRGs by Rambourg et al. (16).
Effects of tonicity and temperature on release of SP. The effects of hypertonic and hypothermic conditions upon the release of SP from cultures are shown in Fig. 4. Compared with the unstimulated control group (isotonic assay buffer at $37^{\circ} \mathrm{C}$, corresponding to zero added mOsm/liter in Fig. 4), hypertonic mannitol caused substantial dose-dependent augmentation of fractional SP release, which was statistically significant at the two highest osmolarities studied ( $P<0.001$ each, Dunnett's); both $10 \mu \mathrm{M}$ capsaicin and $50 \mathrm{mM} \mathrm{KCl}$ also significantly increased fractional substance $P$ release $(P<0.001$ each, Dunnett's). In marked contrast, exposure of DRG cell cultures to isotonic, hypothermic conditions (i.e., $\mathrm{AB}$ at $25^{\circ} \mathrm{C}$ ) did not augment fractional SP release.

Dose-response relationships between tonicity and fractional SP release for different solutes are shown in Fig. 5. The Cfiber responses to hypertonicity caused by addition of mannitol, sucrose, or $\mathrm{NaCl}$ to isotonic $\mathrm{AB}$ were almost identical. In marked contrast, hypertonic glycerol elicited no augmentation in SP release from these cultured neurons. At the highest concentrations studied, there was no difference in fractional SP release among the mannitol-, sucrose-, and $\mathrm{NaCl}$-exposed wells, but the fractional SP release induced by exposure to $616 \mathrm{mOsm} /$ liter glycerol in assay buffer was significantly lower than that induced by these three solutes $(P<0.001)$. Hypothermia had no influence on fractional SP release, even in the presence of hyperosmolar environment (Fig. 6).

Hypertonicity-induced SP release was not attributable to loss of neuronal cell membrane integrity. Cells exposed to either isotonic or hypertonic conditions continued to exclude trypan blue, while neurons exposed to ethanol as a positive control did stain with trypan blue (data not shown).

\section{Discussion}

In this study, we tested whether hyperosmolarity or hypothermia can directly stimulate tachykinin release from sensory C-fiber 


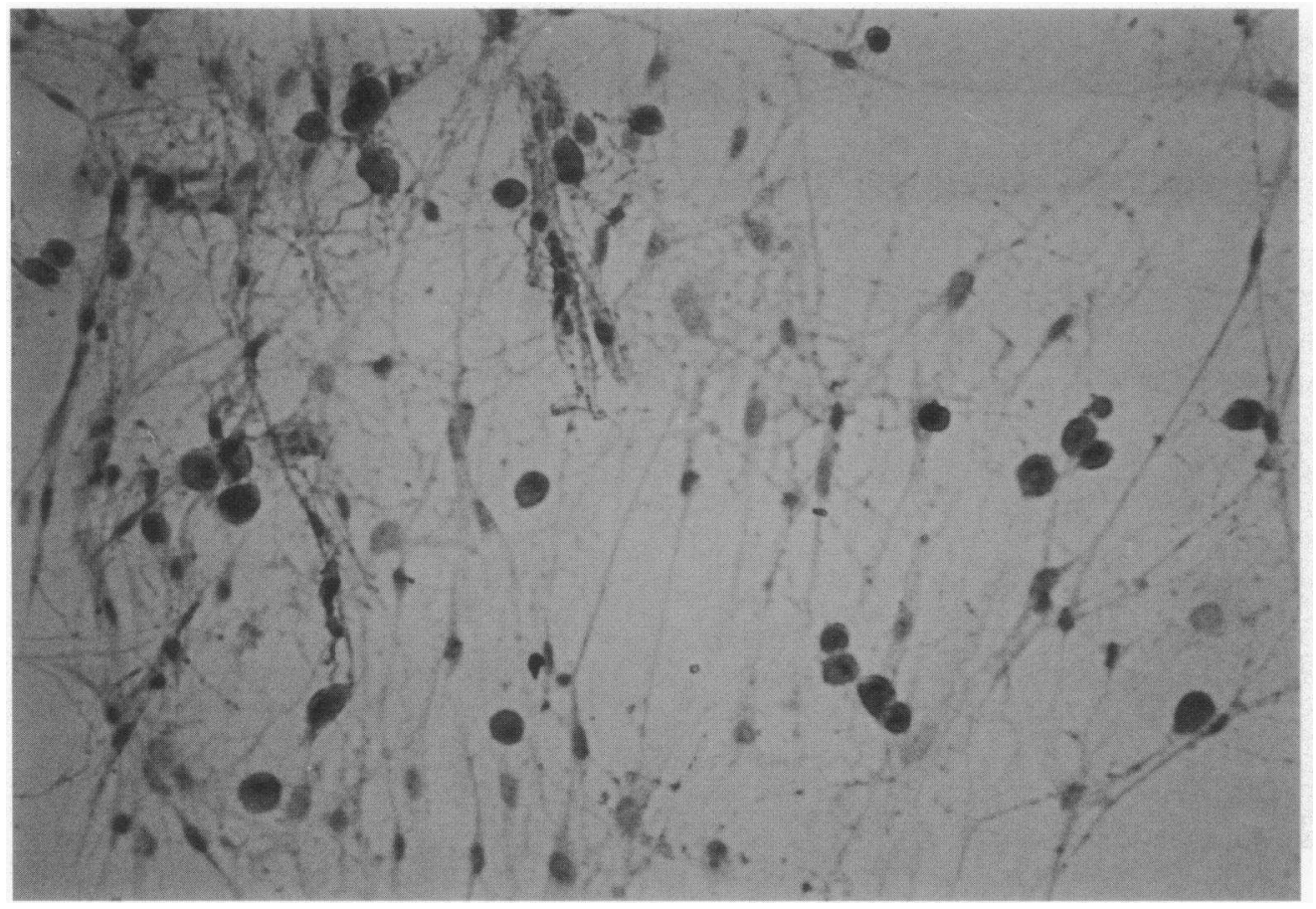

Figure 2. Immunohistochemical stain of typical cultured dorsal root ganglion cells for substance P. Dark staining neurons contain SP.

neurons. We isolated and cultured sensory C-fibers from the dorsal root ganglia of neonatal rats. After $7 \mathrm{~d}$ in primary culture (Fig. 1), these cells were exposed to conditions of hyperosmolarity or hypothermia, alone or together. Our results (Figs. 46) demonstrate that hyperosmolarity, but not hypothermia, stimulates substance $P$ release from these cells. Both mucosal lining fluid hyperosmolarity and mucosal hypothermia have been implicated as likely physical sequelae of dry gas hyperpnea, which provokes tachykinin-dependent bronchoconstriction in guinea pigs. Our present results therefore suggest that if sensory $\mathrm{C}$-fiber activation occurs as a direct consequence of physical sequelae of dry gas hyperpnea, then it is airway drying, rather than airway cooling, which stimulates sensory C-fibers to release their neuropeptides.

We performed these studies in isolated, dissociated neonatal dorsal root ganglion cells in primary culture. The large majority of these cells are sensory C-fibers, as reflected in their elevation of intracellular calcium in response to a modest ( $10 \mu \mathrm{M})$ concentration of capsaicin (Fig. 3). Furthermore, these cells contain substantial amounts of substance $P$, as reflected in our direct measurement by ELISA and predominantly positive immunoreactivity for SP on immunohistochemical stain (Fig. 2). Exposure to nerve growth factor had previously been shown essential for the expression of the preprotachykinin-I gene that encodes SP and NKA (17), and so was included in our experimental design. It is noteworthy that dorsal root ganglion cells do innervate the pulmonary airways below the trachea $(18,19)$, and so should be considered appropriate cells to study in relation to possible mechanisms of hyperpnea-induced bronchoconstriction. We elected not to study nodose ganglion cells, which innervate the trachea and largest central airways (19), because of the small number of neurons that can be isolated from each animal, a limitation that would necessitate the study of an even larger number of animals than those used in the present design.

Previous studies of DRG cells have confirmed the utility of this system for identification of mediators or drugs that stimulate or modulate C-fiber activation. Perney exposed cultured DRG cells to bradykinin, capsaicin, and $\mathrm{KCl}$, and showed that each of these substances directly stimulates tachykinin release (13). A similar approach has provided direct demonstration that both morphine and neuropeptide $\mathrm{Y}$ can each inhibit sensory C-fiber activation and tachykinin release. This system has also been used to identify the calcium channels activated by capsaicin in these cells. Thus, even though cultured DRG cells have only short axons that have regrown during the $7 \mathrm{~d}$ of culture, these cells nonetheless appear to reflect parallel behaviors of intact sensory C-fibers studied in vivo (13).

An important advantage of studying sensory C-fibers in primary culture is that stimuli can be applied in the absence of influences from other cell types. Any tachykinin release observed after application of a given stimulus to isolated DRG cells represents the direct effect of that stimulus upon sensory C-fibers, rather than an indirect effect through other cellular coupling mechanisms. Previous in vitro or in vivo pharmacologic studies have identified a number of inflammatory mediators as "stimulants" of tachykinin release from airway C-fibers, but it seems likely that at least some of these agents act indirectly to activate C-fibers. For example, Martins et al. (20) showed that leukotriene $\mathrm{D}_{4}$, platelet activating factor, and histamine all released tachykinins from isolated tracheally superfused guinea pig lungs. Surprisingly, methacholine and SP also promoted the release of NKA in this system. As neither methacholine nor SP is known to stimulate C-fibers directly, these results suggest that airway constriction per se may have led to the activation of C-fibers in that study. Perhaps mechanical coupling, rather than direct neuronal activation, explains how some or all of the mediators studied led to tachykinin release. Other studies have also concluded that administration of various inflammatory mediators (21-27) or even hypertonic saline (28) stimulate $\mathrm{C}$-fibers to release tachykinins in the airways. Yet because airways contain many cell types capable of releasing their own compounds which might directly stimulate sensory 

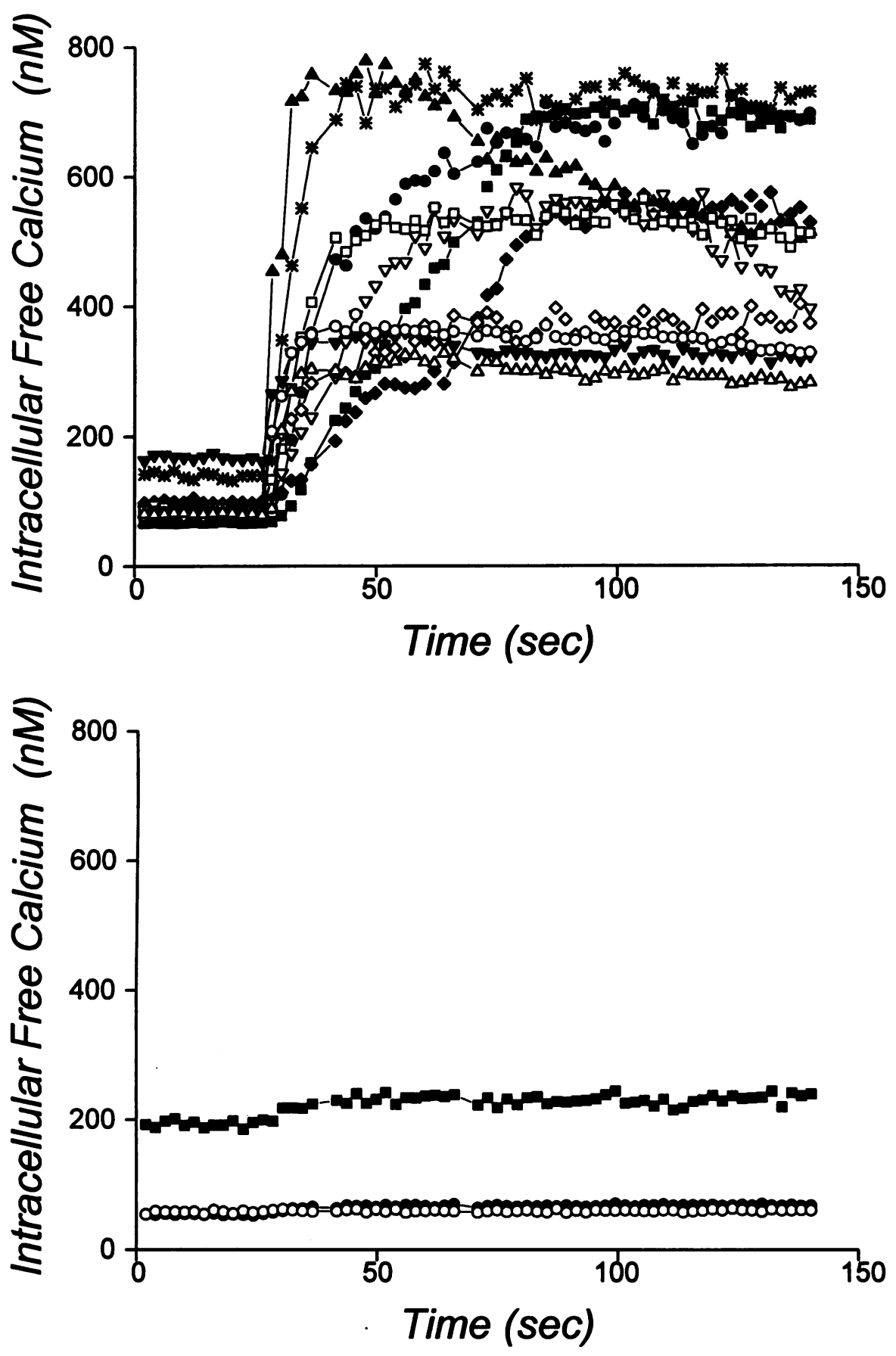

Figure 3. Intracellular free calcium concentration in cultured $\mathrm{C}$-fiber neurons before and during superfusion with $10 \mu \mathrm{M}$ capsaicin. (Top) Responses in eleven individual neurons whose free intracellular calcium concentration increased during capsaicin superfusion. (Bottom) Responses in three individual neurons that did not respond to capsaicin superfusion. In all experiments, capsaicin was introduced into the superfusion system at time $=4 \mathrm{~s}$. Each symbol in each panel represents data from an individual neuron.

C-fibers, and because of the potential for mechanical coupling noted above, it is difficult to be sure whether or not the effect of a putative C-fiber stimulant is actually a direct one. Indeed, one recent report indicates that histamine, known to lead to the activation of C-fibers in vivo (27), has no direct influence upon C-fiber electrophysiology (29).

Our results show that hyperosmolarity can directly stimulate C-fibers to release tachykinins without injurious disruption of the cell membrane. Furthermore, it is likely that neuronal volume change represents the physical stimulus actually transduced by C-fibers, because hyperosmolarity provoked SP release only when induced by the addition of cell-membrane impermeant solutes (mannitol, sucrose, or $\mathrm{NaCl}$ ). In marked contrast, addi- tion of glycerol (which quickly equilibrates concentration across cell membranes) (30) did not cause tachykinin release. One can expect that C-fibers exposed to hypertonic mannitol, sucrose, or $\mathrm{NaCl}$ underwent shrinkage due to water flux to the extracellular compartment, whereas no such neuronal volume change likely occurred in C-fibers exposed to hypertonic glycerol. These results are consistent with the prior observations that an increase in environmental tonicity can elicit neurotransmitter release from other neuronal cell types $(31,32)$. Precisely how C-fibers transduce volume change was not the subject of this study, but might be related to their ability to sense noxious mechanical stimulation $(29,33)$, or perhaps even to the apparent "'mechanical coupling'" suggested above. In contrast, appli- 


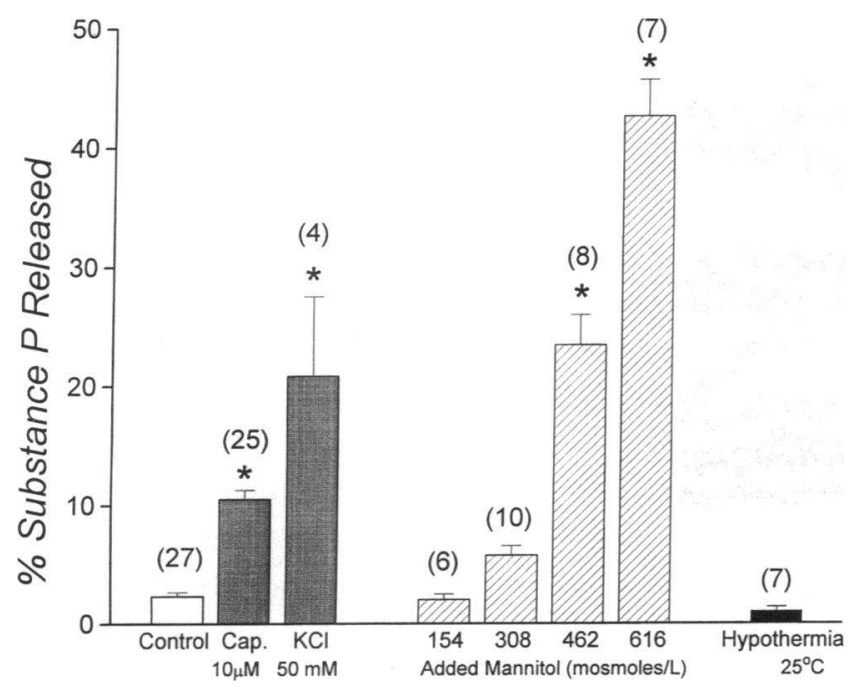

Figure 4. Effects of hypertonicity, caused by addition of mannitol to isotonic assay buffer, and of hypothermia upon release of substance $P$ from cultured C-fiber neurons; zero added $\mathrm{mOsm} /$ liter corresponds to isotonic assay buffer. Values are mean \pm SEM. Compared to isotonic, $37^{\circ} \mathrm{C}$ buffer control, hypertonicity caused a dose-dependent augmentation of substance $P$ release, while hypothermia did not alter release. The responses to the positive controls (capsaicin [Cap.] and $\mathrm{KCl}$ ) are shown for reference. Substance $P$ release is shown as percentage total cellular content. Numbers in parentheses above bars designate number of experiments. ${ }^{*} P<0.001$ (ANOVA followed by Dunnett's multiple range test).

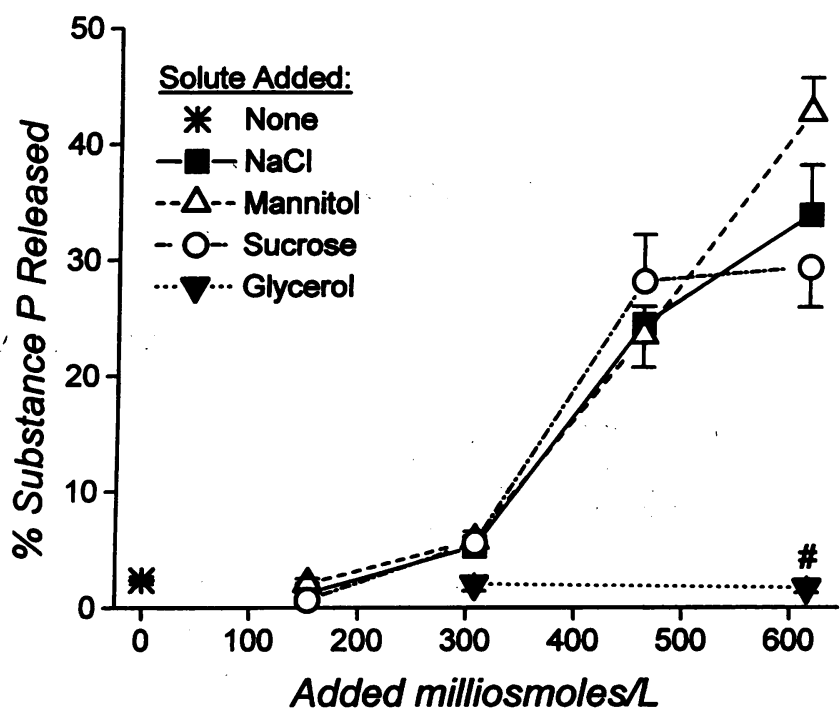

Figure 5. Effect of different solutes upon hypertonicity-induced substance $P$ release from cultured $C$-fiber neurons. Stimulus-response relationships were similar for added mannitol $(\Delta)$, sodium chloride $(\square)$, and sucrose $(O)$, but differed from that for added glycerol $(\nabla)$, which caused significantly less neuropeptide release at the highest concentration (" $P<0.001$, ANOVA with Bonferroni correction followed by Schiffe multiple range test); zero added $\mathrm{mOsm} / \mathrm{L}$ corresponds to isotonic assay buffer (star). Data are represented as the mean \pm SEM. $N$ = 5-10 experiments per condition, except for control condition of no added solute, where $\mathrm{N}=27$ experiments.

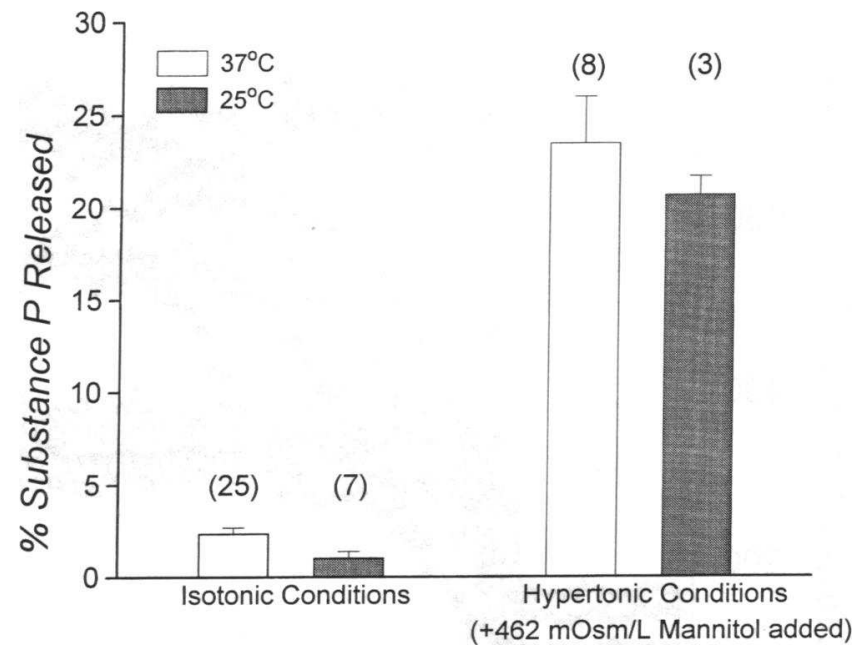

Figure 6. Effect of hypothermic conditions upon substance $P$ release from cultured $\mathrm{C}$-fiber neurons. Release of substance $\mathrm{P}$ at $25^{\circ} \mathrm{C}$ was not significantly different from that at $37^{\circ} \mathrm{C}$, in either isotonic or hypertonic environment. Data are represented as the mean \pm SEM. Numbers in parentheses above bars designate number of experiments.

cation of moderate hypothermia neither stimulated nor suppressed SP release significantly, under isotonic or hypertonic conditions, though there was a trend toward slightly diminished SP release from hypothermic cells (Fig. 6).

We have demonstrated previously that guinea pigs experience hyperpnea-induced bronchoconstriction that closely resembles HIB in human asthma. Although its role in human asthma is unknown, tachykinin release from airway sensory Cfibers plays a critical role in guinea pig HIB. Results from the present study suggest that activation of $\mathrm{C}$-fibers during guinea pig HIB could stem as a direct consequence of mucosal hyperosmolarity induced by airway water loss. That substantial proximal airway water loss can occur under these circumstances seems certain. Van Oostdam et al. (34) and Barbet and colleagues (35) both showed evidence for severe airway dehydration in guinea pigs subjected to dry gas breathing through a tracheostomy. Direct measurements of airstream water vapor fluctuations within the central airways of mechanically hyperventilated dogs (36) also demonstrate that dry gas hyperpnea imposes substantial water losses within the central airways. Even quietly breathing animals develop moderate mucosal hyperosmolarity when breathing dry gas through a tracheostomy (37). Thus, although mucosal surface osmolarity in guinea pigs has never been measured during dry gas hyperpnea, it seems very likely that 2-3-fold elevations of local tonicity could occur and stimulate tachykinin release directly. Direct activation of C-fibers by inhalation of hypertonic saline (28) also seems likely.

It is important to acknowledge some limitations of this study. First, as noted above, we intentionally eliminated indirect coupling mechanisms that could have led to the activation of C-fibers, by studying DRG cells in primary culture. While this approach has the advantage noted above, it does remove the $C$ fiber from extraneuronal influences that are ordinarily present within the intact airway. It is well established that various compounds can "sensitize" or inhibit C-fiber activation by other stimulants $(21-24)$. It is possible that the absence of such 
compounds which might be present within intact airways altered the responses we observed in cultured DRG cells. For example, it is conceivable that in the presence of sensitizing prostaglandins, hypothermia might gain efficacy as a direct activator of C-fibers. Also, it is important to note that the stimuli delivered to cultured DRG neurons in our studies were applied to the entire cell (soma plus axons), whereas only the nerve endings within the airways are exposed to the physical stimuli imposed by dry gas hyperpnea in vivo.

Second, we studied rat dorsal root ganglion cells, but it is guinea pigs that are known to experience tachykinin-mediated HIB. However, we think that species differences are relatively unimportant in this circumstance. Rats clearly demonstrate sensory neuropeptide-mediated airway responses $(28,38)$, and though dry gas hyperpnea does not cause bronchoconstriction in rats, it does cause bronchovascular hyperpermeability (D. W. Ray and J. Solway, unpublished observations ). Also mechanical ventilation with cold dry air elicits bronchovascular leak that depends upon tachykinin release (39) in these animals. In addition, both rodent species exhibit prominent $\mathrm{C}$-fiber airway innervation, with similar lung SP contents (40), and we know of no evidence which indicates that rat and guinea pig sensory nerves behave differentially.

Third, we did not address the possibility that various sensory neuropeptides are released differentially. Thus, it remains conceivable that hypothermia, which does not stimulate C-fiber SP release, may nonetheless activate $\mathrm{C}$-fibers to release neurokinin A or calcitonin gene-related peptide (CGRP). It is thought that SP, NKA, and CGRP are localized together in storage granules that are released from nerve varicosities upon $\mathrm{C}$-fiber activation $(41,42)$, but the possibility of differential neuropeptide release has been raised by previous observations (20) and could alter interpretation of the present results if it occurs.

Lastly, the relevance of the present findings for human airways disease is unknown. The mechanism of hyperpnea-induced bronchoconstriction in asthma is uncertain, and the role of tachykinins in this response is unexplored. It is nonetheless tempting to speculate that airway hypertonicity could occur during dry gas hyperpnea in humans with asthma and so stimulate tachykinin release. That human $\mathrm{C}$-fibers might respond in this way is reflected in long clinical experience that application of salt to a wound increases pain.

In conclusion, we demonstrate that hyperosmolarity, but not hypothermia, stimulates tachykinin release from neonatal rat DRG cells in primary culture. Neuronal volume change represents the key physical stimulus transduced by airway C-fibers in response to dry gas hyperpnea. Airway drying, rather than airway cooling, may be the physical stimulus which activates airway C-fibers and stimulates release of neuropeptides in hyperpnea-induced bronchoconstriction.

\section{Acknowledgments}

We thank Vytautas Bindokas, Ph.D. for his assistance in performing the fura-2 calcium studies. We thank Mary Collins and Donna Jasutis for their assistance in preparation of the manuscript.

This work was supported by National Heart, Lung, and Blood Institute grants HL-41009, HL-02205, HL-08519, HL-48696, and HL-02376, National Institute of Allergy and Infectious Diseases grant AI-34566, and by grants from the Allen and Hanburys Foundation and the American Lung Asssociation.

\section{References}

1. Anderson, S. D., R. E. Schoeffel, R. Follet, C. P. Perry, E. Daviskas, and M. Kendall. 1982. Sensitivity to heat and water loss at rest and during exercise in asthmatic patients. Eur. J. Respir. Dis. 63:459-471.

2. Blackie, S. P., C. Hilliam, R. Village, and P. D. Pare. 1990. The time course of bronchoconstriction in asthmatics during and after isocapnic hyperventilation. Am. Rev. Respir. Dis. 142:1133-1136.

3. McFadden, E. R., Jr., D. R. Stearns, R. H. Ingram, Jr., and D. E. Leith. 1977. Relative contributions of hypcoapnia and hyperpnea as mechanisms in postexercise asthma. J. Appl. Physiol. Respir. Environ. Exercise Physiol. 42:22-27.

4. Sheppard, D., J. Epstein, M. J. Holtzman, J. A. Nadel, and H. A. Boushey. 1982. Dose-dependent inhibition of cold-air-induced bronchoconstriction by atropine. J. Appl. Physiol. 53:169.

5. Zeballos, R. J., R. Shturman-Ellstein, J. F. McNally, Jr., J. E. Hirsch, and J. F. Souhrada. 1978. The role of hyperventilation in exercise-induced bronchoconstriction. Am. Rev. Respir. Dis. 118:877-884.

6. Chapman, R. W., and G. Danko. 1985. Hyperventilation-induced bronchoconstriction in guinea pigs. Int. Arch. Allergy Appl. Immun. 78:190-196.

7. Ray, D. W., C. Hernandez, N. Munoz, A. R. Leff, and J. Solway. 1988 Bronchoconstriction elicted by dry gas hyperpnea in guinea pigs. J. Appl. Physiol. 65(2):934-939.

8. Garland, A., J. E. Jordan, D. W. Ray, S. M. Spaethe, L. E. Alger, and J. Solway. 1993. Role of eicosanoid mediators in hyperpnea-induced airway responses in guinea pigs. J. Appl. Physiol.

9. Ray, D. W., C. Hernandez, A. R. Leff, and J. Solway. 1989. Tachykinins mediate bronchoconstriction elicited by isocapnic hyperpnea in guinea pigs. $J$. Appl. Physiol. 66(3):1108-1112.

10. Garland, A., D. W. Ray, C. M. Doerschuk, M. Jackson, S. Eappen, L. Alger, and J. Solway. 1991. The role of tachykinins in hyperpnea-induced bronchovascular hyperpermeability in guinea pigs. J. Appl. Physiol. 70(1):27-35.

11. Solway, J., B. M. Kao, J. E. Jordan, B. Gitter, I. W. Rodger, J. J. Howbert, L. E. Alger, J. Necheles, A. R. Leff, and A. Garland. 1993. Tachykinin receptor antagonists inhibit hyperpnea-induced bronchoconstriction in guinea pigs. J. Clin. Invest. 92(1):315-323.

12. Eggleston, P. A., A. Kagey-Sobotka, and L. M. Lichtenstein. 1987. A comparison of the osmotic activation of basophils and human lung mast cells. Am. Rev. Respir. Dis. 135:1043-1048.

13. Perney, T. M. 1989. Substance P release, calcium homeostasis, and phospholipid metabolism in dorsal root ganglion neurons in vitro $\mathrm{Ph}$. $\mathrm{D}$. thesis. University of Chicago.

14. Bindokas, V. P., J. R. Brorson, and R. J. Miller. 1993. Characteristics of voltage sensitive calcium channels in dendrites of cultured rat cerebellar neurons. Neuropharmacol. 11:1213-1220.

15. Folkesson, R., A. Neil, and L. Terenius. 1985. Enzyme-linked immunosorbent assay of substance $\mathrm{P}$ and its metabolite $\mathrm{SP}_{1-7}$. A comparison with RIA. $J$. Neurosci. Methods 14:169-176.

16. Rambourg, A., Y. Clermont, and A. Beaudet. 1983. Ultrastructural features of six types of neurons in rat dorsal root ganglia. J. Neurocytol. 12:47-66.

17. MacLean, D. B., S. F. Lewis, and M. F. Wheeler. 1988. Substance P content in cultured neonatal rat vagal sensory neurons: the effect of nerve growth factor. Brain Res. 457:53-62.

18. Lundberg, J. M., T. Hokfelt, C-R Martling, A. Saria, and C. Cuello. 1984. Substance P-immunoreactive sensory nerves in the lower respiratory tract of various mammals including man. Cell Tissue Res. 235:251-261.

19. Kummer, W., A. Fischer, R. Kurkowski, and C. Heym. 1992. The sensory and sympathetic innervation of guinea-pig lung and trachea as studied by retrograde neuronal tracing and double-labelling immunohistochemistry. Neuroscience. 49(3):715-737.

20. Martins, M. A., S. A. Shore, and J. M. Drazen. 1991. Release of tachykinins by histamine, methacholine, PAF, $\mathrm{LTD}_{4}$, and substance $\mathrm{P}$ from guinea pig lungs. Am. J. Physiol. 261:(Lung Cell. Mol. Physiol. 5):L449-L455.

21. Yanagisawa, M., M. Otsuka, and J. E. Garcia-Arraras. 1986. E-type prostaglandins depolarize primary afferent neurons of the neonatal rat. Neurosci. Lett. 68:351-355.

22. Weinreich, D., and W. F. Wonderlin. 1987. Inhibition of calcium-dependent spike after-hyperpolarization increases excitability of rabbit visceral sensory neurones. J. Physiol. 394:415-427.

23. Ueda N., I. Muramatsu, and M. Fujiwara. 1985. Prostaglandins enhance trigeminal substance P-ergic responses in the rabbit iris sphincter muscles. Brain Res. 337:347-351.

24. Ellis, J. L., and B. J. Undem. 1991. Role of peptidoleukotrienes in capsaicin-sensitive sensory fibre-mediated responses in guinea-pig airways. J. Physiol. 436:469-484.

25. Bloomquist, E. I., and R. M. Kream. 1990. Release of substance $P$ from guinea pig trachea leukotriene $\mathrm{D}_{4}$. Exp. Lung Res. 16:645-659.

26. Bloomquist, E. I., and R. M. Kream. 1987. Leukotriene $D_{4}$ acts in part to contract guinea pig ileum smooth muscle by releasing substance P. J. Pharm. Exp. Ther. 240(2):523-528. 
27. Saria, A., C. Martling, Z. Yan, E. Theodorsson-Norheim, R. Gamse, and J. M. Lundberg. 1988. Release of multiple tachykinins from capsaicin-sensitive sensory nerves in the lung by bradykinin, histamine, dimethylphenyl piperazinium and vagal nerve stimulation. Am. Rev. Respir. Dis. 137:1330-1335.

28. Umeno, E., D. M. McDonald, and J. A. Nadel. 1990. Hypertonic saline increases vascular permeability in the rat trachea by producing neurogenic inflammation. J. Clin. Invest. 85(6):1905-1908.

29. Fox, A. J., L. Urban, A. Dray, and P. J. Barnes. 1993. Characterisation of single vagal afferent fibers in guinea-pig airways using a novel in vitro preparation. Am. Rev. Respir. Dis. 147(4, Part 2):A816.

30. Dooley, D. C. 1982. Glycerol permeation of the human granulocyte. Exp. Hematol. 10:413-422.

31. Fatt, P., and B. Katz. 1952. Spontaneous subthreshold activity at motor nerve endings. J. Physiol. (Lond.). 117:109-128.

32. Bekkers, J. M., and C. F. Stevens. 1989. NMDA and non-NMDA receptors are co-localized at individual excitatory synapses in cultured rat hippocampus. Nature (Lond.). 341:230-233.

33. Dray, A., and J. N. Wood. 1991. Nonopioid molecular signaling mechanisms involved in no-ciception and antinociception. In Towards a New Pharmacotherapy of Pain. A. I. Basbaum and J.-M. Besson, editors. John Wiley \& Sons, Ltd. 21-33.

34. Van Oostdam, J. C., D. C. Walker, K. Knudson, P. Dirks, R. W. Dahlby, and J. C. Hogg. 1986. Effect of breathing dry air on structure and function of airways. J. Appl. Physiol. 61 (1):312-317.

35. Barbet, J. P., M. Chauveau, S. Labbe, and A. Lockhart. 1988. Breathing dry air causes acute epithelial damage and inflammation of the guinea pig trachea. J. Appl. Physiol. 64:1851-1857.

36. Ray, D. W., E. P. Ingenito, M. Strek, P. Schumacker, and J. Solway. 1989. Longitudinal distribution of canine respiratory heat and water exchanges. J. Appl. Physiol. 66(6): 2788-2798.

37. Boucher, R. C., M. J. Stutts, P. A. Bromberg, and J. T. Gatzy. 1981. Regional differences in airway surface liquid composition. J. Appl. Physiol. 50:613-620.

38. McDonald, D. M. 1988. Respiratory tract infections increase susceptibility to neurogenic inflammation in the rat trachea. Am. Rev. Respir. Dis. 137(6):14321440.

39. Yoshihara, S., B. Chan, I. Yamawaki, P. Geppetti, F. L. M. Ricciardolo, and J. A. Nadel. 1994. Exposure to cold air increases plasma extravasation in the rat trachea by tachykinin release from sensory nerves. Am. J. Respir. Crit. Care Med. 149(4, Part 2):A891. (abstract)

40. Lundberg, J. M., T. Hokfelt, C. R. Martling, A. Saria, and C. Cuello. 1984. Substance P-immunoreactive sensory nerves in the lower respiratory tract of various mammals including man. Cell Tissue Res. 235:251-261.

41. Merighi, A., J. M. Polak, S. J. Gibson, S. Gulbenkian, K. L. Valentino, and S. M. Peirone. 1988. Ultrastructural studies on calcitonin gene-related peptide-, tachykinins- and somatostatin-immunoreactive neurones in rat dorsal root ganglia: evidence for the colocalization of different peptides in single secretory granules. Cell Tissue Res. 254:101-109.

42. Martling, C. R. 1987. Sensory nerves containing tachykinins and CGRP in the lower airways. Functional implications for bronchoconstriction, vasodilatation and protein extravasation. Acta Physiol. Scand. Suppl. 563:1-57. 